\title{
A RELEVÂNCIA DA VAGUEZA PARA A TRADUÇĀO, ILUSTRADA COM EXEMPLOS DE INGLÊS PARA PORTUGUÊS
}

\section{Diana Santos *}

\begin{abstract}
RESUMO: Este artigo aborda a noção de vagueza com algum pormenor, de forma a defini-la de uma maneira útil para a descrição gramatical e sobretudo para o contraste entre duas linguas. O objectivo principal é demonstrar como este conceito é importante na traduçāo (e consequentemente também na análise desta).

Além de interpretar (uma parte das) escolhas do tradutor como devidas à existência de vagueza contrastiva, proponho que os sistemas gramaticais em bloco também devem ser comparados, sugerindo a relevância para esse efeito dos conceitos de vagueza gramatical e vagueza gramatical contrastiva.

Apresento de seguida uma vasta gama de exemplos de tradução de inglès (americano) para portuguès (de Portugal), que ilustram os problemas causados por estes dois tipos de vagueza na área do tempo e aspecto.
\end{abstract}

UNITERMOS: tradução; estudos contrastivos; tempo; aspecto; portuguès; inglès.

\section{Introdução}

Não é raro ler-se que, se não for possivel manter um enunciado vago na lingua de destino, o tradutor tem de escolher uma tradução sem poder recorrer a um critério objectivo. Esta afirmação está associada à ideia, já clássica, de que linguas dife-

(*) Departamento de Estudos Britânicos e Norte-Americanos, Universidade de Oslo, Noruega. 
rentes identificam bocados diferentes da realidade (cf. Lyons (1968:9.4.6) ou Bassnett-McGuire (1980, p. 30-1)). No entanto, os exemplos mencionados restringem-se muitas vezes a casos exóticos envolvendo camelos ou neve, de importância prática diminuta nos dias de hoje.

O meu objectivo é apresentar aqui um outro tipo de vagueza - a que chamarei vagueza gramatical -, e mostrar que, esta sim, constitui uma dificuldade considerável para a tradução quotidiana. Primeiro, pretendo sublinhar que a vagueza é uma propriedade essencial da linguagem natural - não nos encontramos, pois, em presença de um fenómeno explicável em termos de diferenças acidentais entre duas linguas. Em segundo lugar, quero mostrar que, quando os sistemas de duas linguas (inerentemente vagos) são postos frente a frente, nos apercebemos de um muito maior número de diferenças entre essas duas línguas.

Este artigo apresenta de forma condensada uma das conclusōes mais importantes da investigaçāo que conduziu à minha tese de doutoramento (Santos, 1996), cujo objectivo era contrastar os sistemas de tempo e aspecto do português e do inglês. Tendo analisado centenas de pares original-tradução, fui obrigada a reconhecer que, quanto mais fina a análise, mais contrastes se tornam visiveis, e que esses contrastes, na sua maioria, giram em torno da noção de vagueza.

\section{O conceito de vagueza}

Uma tarefa central no contexto do presente artigo é pois clarificar o que pretendo transmitir com o termo vagueza, que não sendo excepção entre os termos gerais em linguística, tem uma definição vagamente partilhada por todos, mas é, de facto, empregue de tantas formas diferentes quantas os investigadores que o usam. (Outro exemplo flagrante dessa situaçāo é o conceito de aspecto, de onde provém a maior parte dos exemplos deste artigo.)

Vagueza pode ser, numa primeira análise, apresentada como o oposto de uma definiçāo precisa. Esta definição, contudo, 
abrange pelo menos os conceitos de subespecificação, imprecisão, ambiguidade e talvez também redundância. ${ }^{1}$

Como me esforçarei por tornar claro nas páginas que se seguem, a forma como pretendo definir vagueza como um conceito útil para a investigação linguística não abrange todas as formas de subespecificação (apenas aquelas que classifico como relevantes) nem de imprecisão (só imprecisão sistemática); e contrasta com (ou seja, opōe-se segundo alguns critérios, a) ambiguidade. Além disso, e independentemente da redundância impedir ou não uma definição precisa, este último conceito não está, simplesmente, relacionado com a vagueza que pretendo definir.

Vagueza é um atributo de uma classificação (ou esquema classificativo). Um objecto pode pois ser vago em relação a tantas classificaçōes quantas lhe forem aplicadas. A primeira definição de vago pode pois ser: quando a um objecto (linguístico) pode ser atribuida, num dado esquema classificativo, mais do que uma classificação, então esse objecto é vago em relação à distinção efectuada pelos dois valores. ${ }^{2}$ Esse objecto pode então ser usado como membro de qualquer das duas categorias, e pode ser interpretado como representando ambas. Além disso, um falante pode usar lo objecto vagol sem se preocupar em decidir por uma das alternativas (Keenan, 1978, p.173, tradução minha).

Na próxima secção, ilustro a ubiquidade do fenómeno da vagueza tal como foi definida aqui, aplicando a definiçāo abstracta a várias situaçōes concretas em linguística.

\section{Vários casos de vagueza}

Um dos casos mais discutidos de vagueza ocorre quando a classificação é feita em termos de uma quantidade objectiva (como

(1) De facto, neste vasto leque de interpretaçōes possiveis pode verse a vagueza do próprio conceito de "oposto"; veja-se, por exemplo, Lyons $(1968: 10.4 .1 ; 1977: 9.1-2)$ sobre os vários fenómenos linguisticos que podem ser distinguidos.

(2) Para tornar as coisas mais simples, vou supor no que se segue que um objecto tem duas classificaçōes e nāo mais. Mas é claro que uma palavra ou frase pode ser vaga entre três ou mais interpretaçōes. 
nos casos careca vs. nāo careca ou fleuve vs. rivière). Para classificar uma pessoa com pouco cabelo ou um rio de tamanho médio em francês podemos (em alguns casos, pelo menos) classificar o rio tanto como fleuve como rivière, e o homem como careca ou nāo. As palavras em si sāo claras e suficientemente precisas para serem empregues pelos falantes sem dar origem a malentendidos, mas não existe uma definição bem delimitada destes conceitos em termos do mundo real. Se pensarmos que em semântica uma das formas de definir (parcialmente) o significado de uma palavra é como o conjunto de objectos que denota (ou pode denotar), vemos que existe um grupo de objectos que pertencem aos dois conjuntos (cada conjunto definindo um termo). Podemos pois chamar a este tipo de vagueza referencial, como Kempson (1977, p. 124), visto que muitos possiveis referentes são vagos em relação às palavras que se lhes referem (em relação à classificação efectuada pela língua). ${ }^{3}$

Um caso parecido é o das palavras a que Lyons (1977:9.1) chama, na esteira de Sapir (1944), opostos graduáveis ("gradable opposites"), ou seja, palavras cujo sentido depende de uma comparação implicita, tais como grande/pequeno, bom/mau, simpático/antipático. Como na definição destes termos nāo entra uma delimitação precisa em termos de uma norma, muitos objectos, quando sujeitos a este tipo de classificaçāo, resultam vagos entre, por exemplo, grande e não grande.

Ora é preciso notar que a vagueza referencial é absolutamente essencial numa lingua, como Keenan salienta: a linguagem humana tem de ser imprecisa para permitir uma comunicaçāo eficiente (Keenan, 1978, p. 160, tradução minha). ${ }^{4}$ É certo que, se

(3) Note-se que, na minha definição, não são as palavras que são vagas. Elas apenas têm contextos de aplicação (denotaçōes) não disjuntos. A vagueza existe só na classificação das entidades fisicas através destas palavras. Note-se o paralelo entre falecer e morrer: estas palavras não são vagas em relação ao nivel de língua, os contextos em que são apropriadas é que se intersectam.

(4) Ninguém certamente afirmará que uma língua seria melhor se definisse o conceito de calvicie em termos do número exacto de cabelos, ou identificasse rios em termos da largura exacta do seu leito. Contudo, também ninguem pode negar que tais definiçōes seriam precisas e bem delimitadas. 
outras línguas têm outros tipos de imprecisão, i.e., se dividem a realidade de formas diferentes, isto pode complicar o processo de tradução (na ausência do referente que o texto origem menciona, note-se) visto que o tradutor tem de adivinhar, fazer uma suposiçāo. No entanto, e embora esta questão seja das mais discutidas na literatura, não é, de forma alguma, o maior problema que a vagueza constitui para a tradução: o número de textos que dependem crucialmente de uma identificação fisica muito precisa contam-se pelos dedos; além disso, essa necessidade pode ser satisfeita através de notas do tradutor.

Um outro tipo de vagueza para que quero chamar a atenção, e a que chamarei vagueza contrastiva, encontra-se implícito na prática corrente da tradução e aprendizagem de uma lingua estrangeira, embora nāo seja reconhecida como tal: nos estudos contrastivos ou na lexicografia bilingue é costume classificar palavras ou expressōes em termos de outra língua, que pode pois ser vista como um sistema classificativo. ${ }^{5}$ De facto, uma tradução fora de contexto (tal como a presente num dicionário bilingue) é uma classificação em que, em regra, existe mais do que um candidato - entradas com uma tradução única são rarissimas na maior parte dos pares de linguas. E o mesmo acontece com caracteristicas gramaticais, como foi apontado por Nida (1959) e popularizado por Kameyama et al. (1991) na área de tradução automática sob o nome infeliz de "translation mismatches" (desajustes na tradução). ${ }^{6}$

Em si, esta vagueza nāo é necessariamente um problema, contudo, se em todos os contextos for evidente para o utilizador do dicionário (ou tradutor) que classificação (ou tradução) usar. O cerne da questão é o grau de sobreposição (ou partilha de significado) dos vários candidatos. (Como discutirei mais à frente, se os candidatos näo partilharem qualquer contexto, a palavra da língua origem não ê vaga, mas simplesmente ambigua.) Guanto mais divergirem, mais fácil é distingui-los (nāo hâ hesitação possivel entre traduzir aterrar por terrorize ou por land em inglês).

(5) Dyvik (1997) defende mesmo esta abordagem como um programa de semântica, propondo redefinir as próprias noçōes de ambiguidade e de vagueza relativas a outra lingua.

(6) Para uma critica desta nomenclatura, veja-se Santos (1996:3.3). 
Os exemplos da Tabela 1, de português para inglês ou alemāo, ilustram casos de mais dificil escolha, precisamente porque existe algo de comum (expresso na terceira coluna, em inglês) que indica que seria possivel usar a palavra no texto fonte sem decidir conscientemente.

Tabela 1

\begin{tabular}{|l|l|l|}
\hline conhecer & $\begin{array}{l}\text { know } \\
\text { meet }\end{array}$ & $\begin{array}{l}\text { be acquainted with } \\
\text { get acquainted with } \\
\text { (people) ingest food } \\
\text { (animals) ingest food } \\
\text { fressen }\end{array}$ \\
\hline comer & $\begin{array}{l}\text { heaven } \\
\text { sky }\end{array}$ & $\begin{array}{l}\text { spiritually above earth } \\
\text { physically above earth }\end{array}$ \\
\hline deixar & $\begin{array}{l}\text { leave } \\
\text { let }\end{array}$ & $\begin{array}{l}\text { abandon place } \\
\text { abandon control }\end{array}$ \\
\hline ficar & $\begin{array}{l}\text { get } \\
\text { remain }\end{array}$ & $\begin{array}{l}\text { new result state } \\
\text { continuing result state }\end{array}$ \\
\hline lago & $\begin{array}{l}\text { pond } \\
\text { lake }\end{array}$ & $\begin{array}{l}\text { small-sized } \\
\text { large-sized }\end{array}$ \\
\hline retirar & $\begin{array}{l}\text { remove } \\
\text { retreat, leave }\end{array}$ & $\begin{array}{l}\text { move things out of a place } \\
\text { move self out of a place }\end{array}$ \\
\hline enganar & $\begin{array}{l}\text { cheat } \\
\text { fail, be wrong }\end{array}$ & $\begin{array}{l}\text { induce others in error } \\
\text { induce self in error }\end{array}$ \\
\hline oferecer & $\begin{array}{l}\text { give } \\
\text { offer }\end{array}$ & $\begin{array}{l}\text { unconditional transfer } \\
\text { conditional transfer }\end{array}$ \\
\hline passar & $\begin{array}{l}\text { spend } \\
\text { cross, go by }\end{array}$ & $\begin{array}{l}\text { leave behind in time } \\
\text { leave behind in space }\end{array}$ \\
\hline
\end{tabular}

Note-se que nāo pretendo afirmar que a escolha entre as duas opções seja sempre, ou sequer na maioria dos casos, problemática; apenas insisto na possibilidade de haver alguns contextos em que seja dificil.

De qualquer forma, a principal mensagem do presente artigo não é relativa a lexemas contrastivamente vagos, apresentados primeiro apenas para salientar as semelhanças com outro tipo de vagueza, que se refere à classificação em termos das categorias definidas pela própria lingua ${ }^{7}$, e a que chamo vagueza

(7) O meu termo "categorias", ou mais precisamente categorias gramaticais, deve ser entendido no sentido lato de "todas as distinçōes reflectidas no sistema linguistico". 
gramatical. Tal vagueza pode ter consequências sẻrias para a tradução, assim como a correspondente vagueza contrastiva (gramatical).

Começo por clarificar o conceito de vagueza gramatical monolingüe.

Nāo sou evidentemente a primeira a notar que as categorias gramaticais não são bem delimitadas, nem fáceis de definir (veja-se outra vez Lyons (1977:1 1.1)). Também o paralelo entre a categorização gramatical e a categorização do mundo subjacente à linguagem natural foi defendido por Taylor (1989) no seu livro intitulado Linguistic categorization.

O meu interesse é olhar para a situação descrita por Taylor numa perspectiva complementar, ou seja, mostrar que a polissemia (ou semelhança familiar) das categorias gramaticais é indissociável do facto de diferentes categorias terem membros comuns. Por outras palavras, algumas expressōes de uma lingua podem ser classificadas como pertencendo a mais do que uma categoria. Esta caracteristica foi notada por Dahl (1985), que usa o termo multidimensional impreciseness para descrever categorias prototipicas em termos de um conjunto de critérios independentes. Elementos obedecendo apenas a alguns critérios (e não a todos) seriam pois vagos. (A propósito, uma análise interessante desta situação seria considerar, na definição dessas categorias, a conjunção $e$ como vaga entre conjunção lógica e união de conjuntos, como Kempson (1977:8.1) sugere para a conjunçăo or.)

Ilustro a vagueza gramatical com "gramática elementar" portuguesa:

- Categoria gramatical: em Ele é amigo do Pedro, amigo é adjectivo ou nome ${ }^{9}$ Por um lado, amigo pode ser modi-

(8) Exemplos retirados das minhas aulas de gramática aos alunos de Português do Departamento de Linguas Clássicas e Romānicas da Universidade de Oslo, em 1996 e 1997.

(9) De notar que adjectivo e nome são, essencialmente, categorias da gramática portuguesa, que não correspondem, portanto, necessariamente aos adjective e noun ingleses. De facto, uma das ideias que pretendo transmitir no presente artigo é precisamente a de que é tão premente uma gramática/sintaxe contrastiva como uma lexicologia/lexicografia contrastiva. 
ficado por muito como é a regra para os adjectivos; por outro lado, a frase é análoga a ele é tio do Pedro, sendo tio indiscutivelmente um nome.

- Que verbo de cópula, ser ou estar? Em Apaixonado, recusou o convite, ele recusou porque estava apaixonado, ou porque é um ser apaixonado, que reage com paixão?

- Adjectivo ou participio passado? Em O muro pintado de branco tem de ser deitado abaixo, referimo-nos ao muro que está pintado de branco ou que foi pintado de branco?

- Se passivo ou inergativo ${ }^{10}$ ? Em $O$ barco afundou-se, estamos a afirmar, em linguagem coloquial, que o afundámos, ou apenas que aconteceu o barco afundar-se?

- Se recíproco ou reflexo? Em Eles encontraram-se na praia, encontraram um ao outro, ou descobriram que estavam na praia?

- Inceptivo ou estativo? Em Conhecer pessoas como ele é uma aventura, referimo-nos a ser conhecido delas ou encontrá-las pela primeira vez?

- Gerúndio temporal ou causal? Em Uma vez, passando por casa dela, lembrei-me do irmáo, estou a dizer que me lembrei quando passava por casa dela, ou porque passava por casa dela?

- Gerúndio consecutivo ou temporal? Em Fechei a porta da cozinha, deixando-a nos seus dominios, deixei-a em consequência do fecho, ou fechei ao mesmo tempo que a deixava?

Os exemplos não têm fim. O que é importante realçar é que com eles apenas pretendo ilustrar a variedade de formas que a vagueza gramatical pode tomar, e nāo indicar problemas na compreensāo das frases. Pelo contrário, muitas vezes as perguntas formuladas nāo são relevantes para o falante: o mais natural seria responder "queria dizer ambas as coisas". O que é importante é que essas mesmas perguntas podem ser cruciais para o tradutor!

Outra fonte (indirecta) que aponta para a importância da vagueza gramatical sāo as alusōes frequentes a esta na literatura de Linguistica computacional / Processamento de linguagem

(10) Seguindo a nomenclatura de Mateus et al. (1989). 
natural. Senão vejamos: na detecção de a que sintagma nominal um dado sintagma preposicional se refere, a percentagem de exemplos vagos entre ligar-se ao verbo ou ao nome, considerando que uma ligação é indeterminada semanticamente se as situações que verificam o significado associado a uma ligação também tornam o significado associado à outra ligação verdadeiro (Hindle \& Rooth, 1993, p.113, tradução minha) apresentada por Hindle \& Rooth foi de $8,7 \%$ a $21,7 \%$. Da mesma maneira, no que respeita à referência anafórica do pronome it em inglês, Sampson (1987) sustenta que num número significativo de casos não é trivial decidir qual o seu antecedente, por causa da vagueza do texto. Finalmente, a anotaçāo de corpora é apresentada por Leech como uma tarefa dificil precisamente porque as formas são frequentemente vagas entre várias categorias: a nossa experiência de corpora sugere que a incerteza em relação a categorização é muito frequente [... I devido à natureza prototipica, ou esbatida ("fuzzy"), da maior parte das categorias linguísticas (Leech, 1993, p. 280, tradução minha).

De facto, basta pensar que a maior parte das distinçōes relevantes numa lingua (especifica), e que foram portanto categorizadas por linguistas, podem ser neutralizadas em alguns contextos (e são-no além disso no uso da língua), para concluir que se devia conceder mais importância à vagueza gramatical. Essa neutralização pode reexprimir-se em termos de vagueza da seguinte forma: as expressões são vagas em relação às duas (ou mais) características a que se referia a classificação. ${ }^{11}$

(11) Na linguagem do estruturalismo, podemos dizer que a ausēncia de marcação ("unmarkedness") implica vagueza: se uma expressão é não marcada em relação, por exemplo, ao género gramatical, podemos dizer que essa expressão é vaga em relação a todos os géneros possiveis. A ausēncia de marcação não pode ser identificada com a minha definição de vagueza, contudo, apenas incluída nela, visto que uma expressão pode ser vaga entre $A$ ou $B$ sem que nenhum de $A$ ou $B$ seja exprimivel em termos de uma escala de marcação, i.e., A e $B$ não têm necessariamente de se encontrar em oposição privativa ou equipolente para uma expressão ser vaga entre eles. 
O meu principal objectivo neste artigo é mostrar as consequências desta propriedade, a vagueza, para a tradução. Sendo a gramática de qualquer lingua essencialmente vaga, e dado que cada língua (e portanto cada gramática) é diferente, a tradução requer múltiplas escolhas para qualquer expressão, por mais pequena e simples que seja. Porque não sāo apenas as palavras e expressões a traduzir que exigem escolhas, mas também todas as classificações a que a frase pode ser sujeita (e que façam sentido ${ }^{12}$, naturalmente), ou seja, categorias gramaticais, operadores gramaticais, traços estilisticos, referência a entidades extralingüisticas, etc. etc. podem ser vagos contrastivamente - e são-no na maioria dos casos. Além de poderem, como acabei de exemplificar, ser vagos na própria lingua (de forma monolingūe, portanto).

De forma mais explicita:

- quando não há operador gramatical, marcador estilístico, ou mesmo categoria gramatical, equivalente, o tradutor tem de escolher que partes do sentido transmitir;

- quando algumas das caracteristicas gramaticais (ou lexicais, evidentemente) são contrastivamente vagas, o tradutor tem de escolher uma parte do sentido;

- quando a vagueza gramatical na lingua de origem não pode ser preservada, o tradutor tem de escolher que interpretação traduzir.

Ou seja, mesmo uma frase pequena, aparentemente trivial, pode envolver mais problemas do que o simples tomar em conta da vagueza contrastiva lexical, ou da vagueza referencial, faria esperar.

No resto do presente artigo, apresentarei vários exemplos que demonstram a magnitude deste problema em traduçōes reais. Mas primeiro quero voltar à definição de vagueza para a refinar em dois sentidos: contrastando-a com a noção de ambiguidade, e restringindo o tipo de subespecificação que interessa considerar.

(12) Em termos da gramática da lingua de origem, bem entendido. 


\section{Refinando a definiçāo de vagueza}

Em meu entender, nem toda a subespecificação qualifica como vagueza: importa apenas considerar a informaçāo relacionada com a classificaçāo. Assim, uma palavra pode ser vaga, por exemplo, em relaçāo ao género numa lingua em que as palavras podem ser marcadas a esse respeito, mas não pode ser vaga em relação a estar a nevar ou não numa classificação de género, apesar de ser obviamente subespecificada em relação ao tempo.

De facto, o meu conceito de vagueza está inextricavelmente associado à noção de sistema: a vagueza é sistemática e é uma propriedade essencial de qualquer língua. Em contrapartida, a ambiguidade é não sistemática e acidental (embora também muito frequente). ${ }^{13}$

Tanto a vagueza como a ambiguidade podem ser caracterizadas de forma muito geral como casos em que uma expressāo tem mais de uma interpretação / classificação. Contudo, as duas interpretações excluem-se mutuamente no caso da ambiguidade, e não se tivermos uma expressão vaga. Além disso, o fenómeno da vagueza encontra-se tanto na competencia linguistica como no desempenho ("performance"), enquanto a ambiguidade é uma propriedade apenas deste último.

Uma expressāo é vaga entre A e B se A e B tiverem uma intersecção não nula, ou se algum conteúdo for partilhado entre A e B, de forma a ser fácil - e económico - usar o mesmo objecto linguistico para dois objectivos diferentes. Com este requisito, excluimos a possibilidade de ter uma expressão vaga entre $\mathrm{A}$ e não $\mathrm{A}$. Como a vagueza faz parte do sistema linguístico. usá-la é apanágio do conhecimento básico da lingua materna, e como tal, encontra-se automaticamente reflectida no desem-

(13) Quando digo que a ambiguidade è não sistemática estou a referirme ao facto de que a ambiguidade a um determinado nivel tende a ser reduzida (e a expressão desambiguada) a um nivel superior (com mais contexto), enquanto a vagueza pode ser preservada e mantida por uma "conspiração" de todos os niveis. (Por exemplo. a ambiguidade morfológica é geralmente eliminada pelo contexto sintáctico.) 
penho linguístico de qualquer falante. Pelo contrário, a maioria das ambiguidades presentes num dado discurso nāo só não sāo reconhecidas mas são irrelevantes de um ponto de vista comunicativo, e, dai, não causam problemas ao tradutor. ${ }^{14}$

Em último lugar, uma diferença muito importante entre ambiguidade e vagueza é que a escolha de uma das alternativas preserva a informação (se se escolher a certa, naturalmente) no caso de a expressão ser ambigua - se não nos encontrarmos nos casos discutidos na nota anterior - enquanto se a expressão for vaga, seja qual for a escolha resulta sempre em perda, como notaram, entre outros, Kaplan et al. (1989).

Note-se, contudo, que nenhuma das observaçōes feitas acima nos dá um critério objectivo e totalmente abrangente que permita discernir entre ambiguidade e vagueza de forma absoluta. Restam casos em que precisariamos de "entrar dentro da cabeça" do autor para saber se este era indiferente às duas possibilidades ou se, pelo contrário, queria exprimir apenas uma delas; e, neste último caso, se estava consciente da ambiguidade. É preciso não esquecer, no entanto, que um teste e uma definição são coisas diferentes, como Gillon (1990) salienta.

\section{Exemplos de vagueza no par inglês - português}

O primeiro exemplo de vagueza linguistica no dominio do aspecto na lingua inglesa que apresento, e que me apercebi de que causava grande número de problemas para a traduçāo para português, diz respeito à classe aspectual inglesa cujos mem-

(14) Excluindo evidentemente os casos em que ambiguidade é intencional, ou percepcionada (veja-se Poesio, 1995) - como em piadas, ou, segundo Rydning (neste volume), em algum discurso politico-, e é portanto relevante funcionalmente no sentido de Catford (1967). Nesses casos estamos provavelmente em presença de uma troca verbal intradutivel, mas tal nāo é relevante no contexto do presente artigo (ainda que este tipo de problema seja muito mais discutido na literatura). De acordo com a minha definição, tais casos são claramente ambíguos, não vagos. 
bros chamei acquisitions (e que passarei a referir por aquisiçōes inglesas), ou seja, expressões vagas entre um estado e o acontecimento que dá origem a esse estado, e em favor de cuja existência argumentarei copiosamente.

De forma a poder dar uma ideia da grande variedade dos casos de vagueza gramatical contrastiva discutidos em Santos (1996), apresentarei também de seguida, embora de forma reduzida, outros exemplos.

\section{A tradução de aquisições inglesas para português}

A existência de verbos e expressões vagas entre um estado e a sua incepção encontra-se bem documentada na literatura sobre tempo e aspecto em inglês, como argumento em Santos (1996:7.1.2).

Para mostrar que tal causa problemas para a tradução para português, o exemplo melhor é o verbo to be, já que as suas traduções padrão ("standard translations", na nomenclatura de Gellerstam (1986)), ser e estar, não podem ser usadas para descrever o inicio de um estado ou propriedade. Mas também me dei conta, no meu estudo, de que a passiva, os verbos de posição e os próprios verbos de percepção ingleses ${ }^{15}$ incluiam essa vagueza, ou por outras palavras, tinham um comportamento de acquisitions.

Como é que um corpus de traduções pode provar, ou, pelo menos, confirmar que uma dada expressão ou classe de expressões ê vaga? Neste artigo, uso vários métodos: em primeiro lugar, apresento frases genuinamente vagas em inglês, tornando essa vagueza explicita fazendo perguntas a que o texto de origem não responde; em segundo lugar, como indicio de que tal vagueza causou problemas ao tradutor (se bem que não necessariamente de forma consciente), apresento traduçōes "problemáticas", ou, pelo menos, traduçōes alternativas que considero, se não melhores, pelo menos igualmente aceitáveis. Em terceiro lugar, apresento aquilo que considero como traduções que preservam a vagueza; finalmente, apresento alguns

(15) Sobre estes últimos, veja-se Santos (no prelo, b). 
dados quantitativos para mostrar que não me refiro a fenómenos isolados. ${ }^{16}$

Começo por dois exemplos com os verbos be e have, tradicionalmente considerados como sendo protótipos de estatividade, e que foram traduzidos por acontecimentos em português:

(1) And she was silent, for his voice was command.

Ela calou-se, porque a voz dele era uma ordem.

'E ela estava em silêncio porque a voz dele era de comando.'

(2) Then, snarling, Kino had it, had it in his fingers, rubbing it to a paste in his hands.

Entāo Kino soltou um grito e agarrou-o, agarrou-o com os dedos, esborrachou-o nas mãos.

'Então, aos gritos, Kino tinha-o na mão, tinha-o entre os dedos, esfregando-o até ficar com uma pasta nas māos.'

O exemplo seguinte contém um verbo de posiçāo do corpo humano inglês, que é sabido poder querer dizer quer "acçāo que dá origem à posiçāo" quer a própria posição. Ou seja, estes verbos sāo simplesmente vagos entre as duas alternativas.

(3) After a while they lay down together on the sleeping mat.

Momentos depois, estavam estendidos, lado a lado, na esteira.

'Dali a pouco tempo deitaram-se juntos na esteira.'

O que torna o exemplo (3) particularmente interessante, contudo, é que todos os linguistas que consultei (na sua maioria falantes nativos de línguas germânicas) o consideraram como um erro de tradução. Mas o facto de que o tradutor cometeu esse erro (?) indica precisamente que teve uma escolha a fazer (e se enganou). Note-se que a sua escolha não foi arbitrária, mas condicionada pela possivel vagueza do original.

(16) Os exemplos são extraídos de The Pearl, de John Steinbeck, Bantam Books, 1975 (primeira edição, 1945), traduzido para português de Portugal por Mário Dionisio: John Steinbeck, A pérola, Publicaçōes Europa-América, 1977. Após os exemplos em itálico, forneço em alguns casos uma tradução (entre pelicas) para português da frase original inglesa que permita a um leitor não familiarizado com a lingua inglesa seguir o argumento. Outras vezes sugiro mesmo uma tradução alternativa, identificada por "ALT:".

TradTerm, 5(1), $1^{\circ}$ semestre de 1998, p. 41-70 
Nāo me interessa aqui discutir a qualidade de traduções especificas; o que me move è o desejo de mostrar que existem outras traduções para as frases em questão que, escolhendo a interpretação alternativa, também qualificariam como aceitáveis naquele contexto particular. Os exemplos seguintes apresentam simultaneamente a tradução publicada e a alternativa (insisto, sem qualquer intuito critico):

(4) and any children who showed a tendency to scuffle, to scream, to cry out, to steal hats and rumple hair, were hissed to silence by the elders.

Se qualquer criança tentava brigar, gritar, chorar, roubar chapéus ou puxar os cabelos, logo os irmãos mais velhos a obrigavam a estar quieta.

ALT: As crianças que mostrassem agitaçāo (...) eram mantidas em silêncio pelos assobios dos mais velhos.

(5) but having set it up, other forces were set up to destroy it. mas mal o construia, logo outras forças se formavam para o destruir.

ALT: mas, tendo-o construido, outras forças intentavam na sua destruição.

(6) The great pearl was wrapped in an old soft piece of deerskin and placed in a little leather bag and the leather bag was in a pocket in Kino's shirt.

Embrulhou a pérola num velho pedaço de macia pele de veado, meteu-a num pequenino saco de coiro, e o saco de coiro, por sua vez, na algibeira da camisa.

ALT: A pérola estava embrulhada numa velha peça macia de pele de veado e metida num saquinho de couro num bolso da camisa de Kino.

(7) And, looking down, she could see the cigarette of the man on watch.

Por baixo da gruta, Joana viu o cigarro da sentinela.

ALT: Olhando para baixo, via o cigarro do homem de sentinela.

(8) All of these things Kino saw in the lucent pearl.

Tudo isto Kino via na pérola cintilante.

ALT: Todas estas coisas Kino viu na pérola reluzente.

Noutros casos, a tradução tenta preservar a vagueza usando mecanismos da gramática portuguesa que envolvem uma 
vagueza correspondente. A existência de tais traduções (mais complexas do que seria natural se houvesse uma classe correspondente em português) pode ser vista como mais uma achega que confirma a vagueza do original:

(9) he thought Kino might look toward the place where it was buried. pensava que Kino havia de denunciar com os olhos o lugar onde a escondera.

'ele pensou que Kino podia olhar para o sitio onde (a pérola) estava enterrada.'

(10) He was shaved close to the blue roots of his beard, and his hands were clean.

Barbeara-se até às raizes azuis da barba, tinha as mãos muito limpas.

'Ele estava barbeado quase atê à raiz azul da barba e as suas māos estavam limpas.'

(11) Kino's brother Juan Tomás and his fat wife Apolonia and their four children crowded in the door and blocked the entrance.

João Tomás, irmão de Kino, a gorda Apolónia, mulher dele, $e$ os quatro filhos vieram das suas cabanas, amontoaram-se à porta, barrando a entrada.

'João Tomás, irmão de Kino, mais a sua gorda mulher, Apolónia, e os quatro filhos enchiam/encheram a porta e bloqueavam/bloquearam a entrada.'

O pretérito mais que perfeito dos exemplos (9) e (10), fazendo referência tanto a um acontecimento como ao estado resultante do mesmo, mostrou ser uma forma adequada de traduzir a passiva inglesa, a qual também refere tanto a acção como o resultado. É interessante notar, a propósito, que a escolha desta forma de tradução não é condicionada pela vagueza em contexto do original: a frase inglesa em (9) só se pode referir a um estado. Contudo, a acção que deu origem a esse estado (o acto de enterrar) pareceu suficientemente importante ao tradutor para mudar a voz (de passiva para activa) e incluir o agente. No exemplo (11), por outro lado, o simple past foi traduzido pelo gerúndio, que permite tanto uma interpretação sequencial como simultânea das acções de barrar e amontoar (blocking e crowding).

Estes exemplos resultam talvez pouco convincentes, mas podem ser reforçados por estudos quantitativos, assim como pela 
observação de partes diferentes do sistema. No que se segue, mostro como uma série de estudos independentes, mais pormenorizados, contribuem para a conclusão de que a classe das aquisições é uma realidade palpável na lingua inglesa.

Em primeiro lugar, olhando para as traduçōes do verbo to be no simple past (Santos, 1996:14.2), resumidas na Tabela 2, dei-me conta de que na maioria dos casos em que em português tinha sido usado o pretérito perfeito simples, o verbo utilizado referia um acontecimento, transmitindo quer um aspecto incoativo quer representando uma instância de percepção. ${ }^{17}$

Tabela 2

\begin{tabular}{|l|l|l|l|c|}
\hline be & simple past & 333 & Imperfeito & 264 \\
\cline { 4 - 5 } & & Perfeito & 27 \\
\cline { 3 - 4 } & & Mais que perfeito & 11 \\
\cline { 3 - 4 } & & sintagma prep. & 6 \\
\hline
\end{tabular}

Vejam-se os seguintes exemplos:

(12) Her goading struck into his brain; his lips snarled and his eyes were fierce again.

Estas perguntas incisivas chegaram-the ao cérebro; os lábios entreabriram-se e os olhos de novo se tornaram duros.

'O perguntar dela entrou-lhe pela cabeça dentro; os lábios abriram e os seus olhos estavam determinados outra vez.'

(13) Now the tension which had been growing in Juana boiled up to the surface and her lips were thin.

A angústia que tinha estado a formar-se no coraçāo de Joana veio então à superficie e pôs-lhe os lábios brancos.

'Agora a tensão que tinha vindo a crescer dentro de Joana tinha vindo à superficie e os lábios dela estavam brancos.'

(17) Em pormenor, as excepções a esta regra foram: cinco construçōes de realce; dois casos traduzidos por houve; o caso de uma construção perifrástica inglesa were long in coming; um caso envolvendo um adverbial de duraçāo com a preposiçāo for, que portanto requer o pretérito perfeito; e um caso que pode ser interpretado como uma expressāo idiomática, and that was breakfast, e que será discutido mais à frente quando apresentar a traduçāo portuguesa dos estados ingleses. 
(14) He looked then for weakness in her face, for fear or irresolution, and there was none.

Ele procurou então no rosto da mulher fraqueza, medo ou irresoluçāo. Nada disso achou.

'He searched then in his wife's face weakness, fear or irresolution. Nothing of that did he find.'

Da forma em tudo idêntica, a motivação subjacente à tradução de to be pelo pretérito mais que perfeito é a possibilidade de este se referir tanto a uma mudança de estado como ao próprio estado (cf. Santos, 1996:13.2.1), como mostram os exemplos (15) e (16):

(15) He was growing very stout, and his voice was hoarse.

Tomara-se muito corpulento e enrouquecera.

'Ele estava a ficar muito forte, e a voz dele era rouca.'

(16) He was quiet now.

Agora a criança acalmara.

'Agora ele estava calmo.'

Por outro lado, analisando uma amostra aleatória de cinquenta verbos no simple past (diferentes de to be) traduzidos pelo pretérito imperfeito e outros cinquenta traduzidos pelo pretérito perfeito (veja-se Santos, 1996:14.4.1), encontrei casos similares que acrescentavam incoatividade, ou, pelo menos, que causavam problemas dificeis de resolver numa tradução - notese que tais problemas não surgiriam numa análise monolingüe do inglês.

Nos dois exemplos seguintes, a interpretação alternativa (e correspondente tradução) seriam igualmente naturais.

(17) And the morning of this day the canoes lay lined up on the beach.

Na manhã daquele dia os barcos ficaram na areia.

'On the morning of that day the boats remained ashore.'

ALT: Na manhã desse dia as canoas estavam alinhadas na praia (podiam ver-se as canoas alinhadas na praia)

(18) Each of the three knew the pearl was valueless.

Qualquer dos três achou que a pérola nāo valia nada.

'Any of the three considered that the pearl was worth nothing.'

ALT: Os três sabiam que a pérola não valia nada. 
Além disso, ao estudar esta amostra aleatória tornou-se evidente que a vagueza relativa à sequência ou simultaneidade de duas acções não era preservada na maioria das traduções para português. Com efeito, enquanto que em inglês no simple past na maioria dos casos a interpretaçāo da relaçāo temporal entre duas acções é deixada ao leitor, as duas traduções mais naturais em português (imperfeito e perfeito) tornam explicita uma das ordens possiveis (nos exemplos seguintes, substitua-se o imperfeito pelo perfeito):

(19) "I am sorry, my friend," he said, and his shoulders rose a little to indicate that the misfortune was no fault of his.

- Lamento muito, meu amigo - disse ele. E erguia um pouco os ombros para mostrar bem que nāo tinha culpa nenhuma daquela contrariedade.

(20) The hot sun beat on the earth so that Kino and Juana moved into the lacy shade of the brush, and small gray birds scampered on the ground in the shade.

O sol ardente causticava tanto a terra que Kino e Joana tiveram de procurar a sombra rendilhada dos arbustos, donde pássaros fugiam apressados.

Em terceiro lugar, ao estudar a tradução do simple past pelo pretérito mais que perfeito (cf. Santos, 1996:13.2.1), observei que a maioria dos 39 casos corresponde a aquisiçōes, que o tradutor tinha optado por dessa forma referir ao mesmo tempo o acontecimento e um estado ou posição:

(21) only a few small barnacles adhered to the shell. só algumas pequenas lapas se lhe tinham agarrado. 'só algumas lapas pequenas estavam coladas à concha.'

(22) who squatted on Kino's right hand. que se agachara à direita de Kino. 'que estava agachada à direita de Kino.'

(23) The little hole was slightly enlarged and its edges whitened from the sucking, but the red swelling extended farther around it. a pequenina mancha aumentara um pouco, ocontomo desinflamarase com a sucção, mas toda a bolha vermelha se alargara. ' $O$ buraquinho estava ligeiramente alargado e ao seu rebordo embranquecido devido à sucçāo, mas o inchaço vermelho estava mais espalhado à volta.' 
E o mesmo se passa com a traduçāo da forma passiva inglesa pelo mais que perfeito (Santos, 1996:13.2.2):

(24) for the hundreds of years of subjugation were cut deep in him. Porque centenas de anos de escravidāo tinham cavado fundo nele.

'Porque as centenas de anos de subjugaçāo estavam cavadas nele.'

(25) the torn flesh of the knuckles was turned grayish white by the sea water

ao contacto da água salgada, em volta dos nós dos dedos se acinzentara

'a carne dos nós dos dedos foi transformada em brancaacinzentada pela água do mar'

Em último lugar, e olhando apenas para a tradução portuguesa noutro contexto (relatado em Santos, a (no prelo)), o tradutês ${ }^{18}$ foi bem patente nos casos em que a força de uma aquisição inglesa tinha sido usada no original, e que portanto seriam sempre dificeis de transmitir em português. Dos três exemplos que se seguem, e cujo inglês tento reconstituir após a marca "REC", dois empregam um acontecimento e um estado:

(26) Esta resposta provocou grande excitação entre os animais $e$, assim que o elefante ficou suficientemente longe para nāo os ouvir, logo ali combinaram fazer um concurso, a ver quem conseguia que o elefante desse um salto.

REC: "This answer caused great excitement among the animals and, as soon as the elephant was far enough not to hear them, at once arranged a competition to see who would make the elephant jump'

(Os elefantes nunca saltam, tradução de Carlos Grifo Babo de Elephants never jump de Violet Easton)

(27) E todos tiveram de se pôr em fila e deitar uma moeda para um

(18) O termo tradutês ("translationese") é aqui empregue para designar o desvio em relação à língua de destino que acontece em textos traduzidos, devido à interferência (inconsciente) da lingua de origem (da sua gramática ou do seu léxico); veja-se por exemplo Gellerstam (1986) ou Santos (1995a). No caso em discussão, as frases portuguesas usam palavras ou expressões (como ficou longe) que soam estranhas no contexto. 
capacete dos polícias. Este ficou muito pesado quando caiu lá dentro a última moeda!

REC: 'And all must stand in a queue and throw a coin to a policeman helmet. This was very heavy when the last coin entered it!'

(Viva o Nodi, tradução de Maria da Graça Moctezuma de Hurrah for little Noddy! de Enid Blyton)

(28) O chefe da policia deixou o Nodi guiar o autocarro como recompensa, e ele estava tão entusiasmado que é dificil descrever REC: The police chief let Noddy drive the bus as a reward, and he was so excited that it is difficult to describe' (Viva o Nodi, traduçāo de Maria da Graça Moctezuma de Hurrah for Little Noddy! de Enid Blyton)

$O$ que interessa salientar nestes exemplos é que resultam estranhos precisamente porque o tradutor foi incapaz de exprimir as duas partes da aquisição inglesa.

Em resumo, parece-me claro que este fenómeno - da vagueza entre um estado e o acontecimento que lhe dá origem é não só bastante comum em inglês (é, além disso preservado pelo simple past) como acarreta uma miriade de pequenos problemas no que respeita à traduçāo para português. No entanto, este é apenas um dos muitos casos de vagueza contrastiva que me foi dado apreciar no par inglês-português. Nas secções seguintes proponho-me pois descrever resumidamente alguns outros tipos identificados.

\section{A tradução das actividades inglesas para o português}

Um tipo de vagueza semelhante, entre a incepção de uma actividade e a própria actividade, verifica-se no caso das actividades inglesas (activities). De facto, alguns dos exemplos já apresentados ((21) e (23), envolvendo os verbos adhere e extend), podem ser interpretados desta maneira ${ }^{19}$; outros casos evidentes sāo:

(19) Esta observação aponta para o facto de algumas expressões em inglês serem vagas entre um estado e uma actividade (o que, dada a ubiquidade da vagueza gramatical, não é de surpreender). 
(29) And as Kino raised his right hand to the iron ring knocker in the gate, rage swelled in him, and the pounding music of the enemy beat in his ears, and his lips drew tight against his teeth.

Guando Kino levou a mão direita ao batente de bronze do portāo, a raiva cresceu dentro dele, a música barulhenta do inimigo encheu-lhe os ouvidos, os lábios apertaram-se-lhe contra os dentes.

'E quando o Kino levantou a sua mão direita até ao batente de ferro do portão, a raiva fervilhava nele, e a música pesada do inimigo batia-lhe aos ouvidos, e os lábios apertavamse-lhe conta os dentes.'

Mas esta situação não esgota de forma alguma os problemas que as actividades inglesas implicam: com efeito, estas constituem um problema dificil para a traduçāo para português nāo por serem gramaticalmente vagas em inglês, mas porque não existe uma classe correspondente em português (em defesa desta afirmação, veja-se Santos, 1996:7.1.3). Tal situação leva a que a maioria das actividades seja contrastivamente vaga em relação ao português sem que o seja necessariamente de um ponto de vista monolingue.

Podemos mostrá-lo pelas escolhas feitas pelo tradutor quando o texto de origem contém actividades: Os exemplos (30), (31) e (32) ilustram respectivamente um acontecimento resultativo, uma situação habitual, e um acontecimento semelfactivo (ou seja, que acontece uma vez só). As traduçōes alternativas, porém, apresentam, na mesma ordem, um acontecimento plural, um semelfactivo e um estado:

(30) the neighbours were tumbling from their houses now. Os vizinhos tinham acorrido.

ALT: Os vizinhos vinham aos tropeçōes.

(31) And the rhythm of the family song was the grinding stone where Juana worked the corn for the morning cakes.

o ritmo dessa música familiar vinha da mó com que Joana preparava o milho para a refeição da manhã.

ALT: O ritmo dessa música familiar vinha da mó com que Joana estava a preparar o milho para a refeiçāo da manhā.

(32) It stopped, and its tail rose up over its back in little jerks and the curved thorn on the tail's end glistened. 
imobilizou-se. Em pequenas sacudidelas, foi erguendo a cauda no ar, e, no extremo dela, o ferrão curvo brilhou.

ALT: Parou e a cauda ergueu-se em pequenas sacudidelas. O ferrāo curvo na ponta brilhava.

Estes exemplos mostram portanto que os textos ingleses são (ou podem ser) vagos em relaçāo à presença de resultado, à habitualidade, e em relação à presença ou ausência de incepção, quando está em causa a tradução para português, porque um falante desta língua tem de tomar decisões em relação a essas questōes para os traduzir. ${ }^{20}$

\section{A tradução dos estados ingleses para português}

Uma questão particularmente interessante no contraste entre as duas linguas é a relevância dada, em português, à distinção entre qualidades (ou estados permanentes) e estados (estados temporários), que toma muitas vezes a forma de uma interpretação habitual vs. outra semelfactiva, quando o verbo em questão é um acontecimento. $O$ inglês é fundamentalmente vago

(20) É preciso reconhecer que estes três exemplos, de facto, podem corresponder a três tipos de situações distintas: Ao usar a progressiva, a frase inglesa em (30) não é marcada em relação a resultatividade, mesmo que se considere que a palavra tumble inclui no seu significado lexical a existência de resultado além de especificar a maneira de a acçāo se desenrolar ("manner"). O tradutor desistiu de exprimir a maneira e exprimiu o resultado plausivel em português. Pode-se portanto considerar que este caso apenas ilustra uma adiçāo de conteúdo que não estava presente na frase original. A frase (31), por outro lado, se considerarmos que a lingua inglesa não distingue formalmente entre habitualidade e semelfactividade (cf. a próxima secção), è um exemplo de vagueza contrastiva. Finalmente, (32) corresponde a um caso de vagueza genuina em inglês, entre a incepção e o desenrolar de uma actividade. (A vagueza monolingue pode ser justificada pelo facto de o inglês ter a possibilidade de indicar formalmente esse desenrolar através da forma progressiva, assim como de exprimir sem ambiguidade o começo de uma acção, através do aspectualizador begin.) Seja como for, estes trẽs exemplos ilustram bem as dificuldades na tradução de actividades para português.

TradTerm, 5(1), $1^{\circ}$ semestre de 1998, p. 41-70 
em relaçāo a esta distinção ${ }^{21}$, o que leva a que um tradutor tenha de tomar uma decisão a esse respeito frequentemente.

Os exemplos que se seguem ilustram escolhas diferentes; a tradução alternativa que sugiro pretende clarificar a escolha que foi feita:

(33) On his lap was a silver tray with a silver chocolate pot and a tiny cup of eggshell china, so delicate that it looked silly when he lifted it with his big hand, lifted it with the tips of thumb and forefinger and spread the other three fingers wide to get them out of the way.

Tinha um tabuleiro de prata no colo, com uma chocolateira também de prata e uma finissima chávena de porcelana da China.

tāo delicada que ficava deslocada quando ele a levantava na mão enorme, segurando-a nas pontas do polegar e do indicador de modo que os outros três dedos estendidos lhe nāo tocassem

ALT: tinha um tabuleiro de prata no colo com um bule de cacau de prata e uma chávena de porcelana chinesa, tão frágil que pareceu deslocada quando ele a levantou na sua mão grossa, com as pontas do polegar e do indicador na asa, e os outros dedos esticados para não atrapalhar.

(34) Beside him on a table was a small Oriental gong and a bowl of cigarettes.

Ao lado, na banca de cabeceira, havia um pequeno tantā oriental e um maço de cigarros.

ALT: Numa mesa ao seu lado estava um pequeno tantã oriental e uma jarra com cigarros.

(35) And he drank a little pulque and that was breakfast.

Bebeu um pouco de pulque. Efoi o seu pequeno almoço.

ALT: $E$ bebeu um pouco de pulque, e isso era o seu pequeno almoço habitual.

Embora o pretérito imperfeito também possa ser considerado em alguns casos vago entre as duas possibilidades - des-

(21) Em Santos (1996:6.2.1), considero com algum pormenor a hipótese de o inglês não fazer sequer essa distinçāo, o que levaria a considerar esta situaçāo de vagueza como puramente contrastiva. 
crever uma qualidade ou uma situação particular,$-{ }^{22}$ a sua interpretação não marcada é a habitual, descrevendo um estado de coisas permanente, e não situado no tempo de forma definida. (Uma forma elegante de descrever este contraste é sugerir que o pretérito imperfeito simples se encontra em oposição privativa com a sua forma progressiva, que tem, por seu lado, como única interpretação uma leitura semelfactiva, de uma situação bem localizada em progresso; cf. Santos (1995b)). Daí que, mesmo que a vagueza seja mantida em teoria, as seguintes traduçōes sejam problemáticas:

(36) and now she did a most surprising thing $e$, de repente, saia-se com a mais inesperada das ideias

'e agora ela tinha feito uma coisa extraordinária'

(37) and the thought got into Kino

Era o que Kino também pensava

'e Kino pensou nisso'

Com efeito, analisando apenas o texto em português em contexto, classifiquei estas frases como habituais (ou descrevendo qualidades), e não referindo acontecimentos concretos únicos, como explicado em Santos (1996:10.2.5). O que demonstra que em alguns $\operatorname{casos}^{23}$ a melhor opção não é preservar a vagueza, mas sim escolher uma das duas interpretações, e consequente traduçāo.

\section{A trađução para português do perfect inglês}

Os exemplos anteriores são todos casos em que o inglês é vago em relação a (algumas distinções necessárias para traduzir para) o português. Também há problemas na tradução de inglês para português, contudo, quando é este último que é vago em relação a uma distinção feita em inglês.

Escolhi o present perfect inglês porque no contexto particular do meu corpus este tempo tem um uso adicional além dos

(22) Um exemplo é a interpretação de trabalhava no exemplo (31). A interpretação "naquele momento" não pode ser excluída, mas a interpretação "em geral" é muito mais saliente.

(23) Provavelmente sempre que as duas linguas, quando vagas, tèm elementos marcados inversos. 
muitos que lhe são atribuidos: o seu emprego assinala uma linguagem arcaica, e é empregue sistematicamente nas conversas entre o povo ignorante e o padre. Além disso, o present perfect inglês é usado (cf. Santos (1996:cap12)) para invocar relevância (algo sobre o qual o português é vago), cf. exemplos (38)-(39); para exprimir um agora estendido ("extended now") (que só é sinalizável em português no caso de ocorrências repetidas), exemplo (40); para indicar a existência de resultado (assunto sobre o qual o português ê vago na maioria dos casos, exemplo (41); e/ou para localizar um acontecimento num passado indefinido, exemplo (42):

(38) "This pearl has become my soul."

- Esta pérola tornou-se a minha alma.

(39) now that you have become a rich man.

- Agora, que és um homem rico.

(40) "If that is so, then all of us have been cheated all of our lives." - Se isso é possivel, quer dizer que temos sido roubados toda a vida.

(41) I have come to see the baby vim ver o pequeno

(42) "I have heard him make that sermon," said Juan Tomás.

- Eu ouvi-o fazer esse sermão-disse João Tomás.

De notar que, no caso do present perfect, o tradutor tem de escolher quais destas facetas são apropriadas no contexto (notese que nada impede que mais do que uma o seja!); se nem todas puderem ser simultaneamente expressas na tradução, qual passar para a lingua de destino; além disso, escolher qual a tradução apropriada para essa mesma faceta.

(43) "Oh, my brother, an insult has been put on me that is deeper than my life."

- Ó meu irmão, fizeram-me um insulto que é mais forte do que a vida.

Exemplificando com o exemplo (43), a sua traduçāo não transmite a conotação de relevância para o momento presente, nem o estilo de linguagem arcaica, nem mesmo possivelmente a existência de resultado ${ }^{24}$, o que não quer dizer que seja fảcil fazer melhor.

(24) O tradutor usa a expressão fazer um insulto para tentar exprimir resultatividade (que um insulto cobriu a personagem, que caiu

TradTerm, 5(1), $1^{\circ}$ semestre de 1998, p. $41-70$ 
Não é pois de admirar que uma das caracteristicas do texto original que os tradutores mais costumam deixar para trás seja precisamente o seu nivel de lingua - como foi notado por Gellerstam (1986) e mais recentemente por Baker (1996). A explicação é simples: já têm problemas suficientes ao tentar transmitir (parcialmente) o próprio significado do texto original. De facto, não surpreenderei decerto ninguém se afirmar que não existe em português um mecanismo gramatical que exprima simultaneamente relevância, foque o resultado, situe o acontecimento num agora estendido, e, além disso, tenha conotações arcaicas! Pelo contrário, este exemplo serve para lembrar que os casos mais prototipicos (e, em consequência, melhores de um ponto de vista literário) do uso do present perfect inglès transmitirão toda esta informação. E, por isso, trarāo as maiores dores de cabeça para o tradutor.

\section{Conclusão}

Espero ter convencido os leitores de que a noção de vagueza como definida aqui é indispensável quer no estudo da gramática de uma lingua quer no do contraste entre duas linguas. Nada mais natural do que a uma expressāo linguística ser possivel associar mais do que uma classificação (não sendo, além disso, as classificações disjuntas). Este estado de coisas constitui, no entanto, um dos problemas mais delicados para um tradutor.

No espaço deste artigo, muitos exemplos relevantes ficaram por incluir, assim como não me foi possivel discutir pormenorizadamente cada par apresentado, nem rever outras abordagens sobre o fenómeno da vagueza. Em Santos (1996) é possivel, contudo, ter acesso a mais informação sobre este e outros assuntos relacionados.

nele como uma nódoa, que ainda o atinge), mas na minha opiniāo o objectivo nāo foi totalmente atingido, porque nem a expressāo fazer um insulto é usada em portuguès correntemente, nem o próprio verbo fazer é de facto resultativo ainda que o seu objecto directo possa denotar um resultado: assim, fazer um discurso ou fazer uma cena nāo são resultativos, enquanto fazer um bolo ou fazer um filme o são. 


\section{Agradecimentos}

Agradeço a Signe Oksefjell a leitura critica de uma versão anterior deste trabalho, assim com a Kjell-Johan Sæbø vảrias discussões que muito contribuíram para aclarar as minhas ideias sobre o assunto.

\section{Referências bibliográficas}

BAKER, M. (1996) Corpus-based translation studies: the challenges that lie ahead. In: SOMERS, H. (ed.) Terminology, LSP and Translation: Studies in language engineering in honour of Juan C. Sager. Amsterdam/ Philadelphia, John Benjamins Publishing Company, p. 175-86.

BASSNET-McGUIRE, S. (1980) Translation Studies. London, Routledge. CATFORD, J.C. (1967) A Linguistic Theory of Translation: An Essay in Applied Linguistics. Oxford, Oxford University Press.

DAHL, Ö. (1985) Tense and Aspect Systems. Oxford, Blackwell.

DYVIK, H. J. J. (1997) Semantic Mirrors: A Translational basis for

Linguistic Semantics. Department of Linguistics and Comparative Literature, University of Bergen. Unfinished manuscript, September 1997.

GELLERSTAM, M. (1986) Translationese in Swedish novels translated from English. In: WOLLIN, L. \& LINDgUIST, H. (eds.) Translation studies in Scandinavia. Lund, CWK Gleerup, p.88-95.

GILLON, B. S. (1990) Ambiguity, generality, and indeterminacy: tests and definitions. Synthese 85, p.391-416.

HINDLE, D. \& ROOTH, M. (1993) Structural Ambiguity and Lexical Relations. Computational Linguistics 19, p. 103-20.

KAMEYAMA, M., OCHITANI, R. \& PETERS, S. (1991) Resolving Translation Mismatches With Information Flow. In: Proceedings of the 29th Annual Meeting of the ACL (Berkeley, 18-2 1 June 1991), p. 193-200.

KAPLAN, R. M., NETTER, K., WEDEKIND, J. \& ZAENEN, A. (1989) Translation by Structural Correspondences. In: Proceedings of the 4th Conference of the European Chapter of the ACL (Manchester, 10-12 April 1989), p.272-81.

KEENAN, E. L. (1978) Some Logical Problems in Translation. In: GUENTHNER, F. \& GUENTHNER-REUTTER, M. (eds.) Meaning and 
Translation: Philosophical and Linguistic Approaches. London, Duckworth, p.157-89.

KEMPSON, R. M. (1977) Semantic theory. Cambridge, Cambridge University Press.

LEECH, G. (1993) Corpus Annotation Schemes. Literary and Linguistic Computing 8, p.275-81.

LYONS, J. (1968) Introduction to Theoretical Linguistics. London, Cambridge University Press. . (1977) Semantics. Cambridge, Cambridge University Press, 2 Vols.

MATEUS, M. H. M., BRITO, A. M., DUARTE, I. \& FARIA, H. (1989) Gramática da língua portuguesa. Lisboa, Caminho, $2^{a}$ edição revista $\mathrm{e}$ aumentada.

NIDA, E. A. (1959) Principles of translation as exemplified by Bible translating. In: BROWNER, R. A. (ed.) On Translation. Cambridge, Mass., Harvard University Press, p.11-31.

POESIO, M. (1995) Semantic Ambiguity and Perceived Ambiguity. Research Report, HCRC/RP-68, Human Communication Research Centre, University of Edinburgh, May 1995.

RYDNING, A. F. (Neste volume) La notion d'ambigüité en traduction. SAMPSON, G. (1987) MT: a nonconformist's view of the state of the art. In: KING, M. (ed.) Machine Translation Today: The State of the Art (Proceedings of the Third Lugano Tutorial, 2-7 April 1984). Edinburgh, Edinburgh University Press, p.91-108.

SANTOS, D. (1995) On grammatical translationese. In: KOSKENNIEMI, K. (comp.) Short papers presented at the Tenth Scandinavian Conference on Computational Linguistics (Helsinki, 29-30th May 1995), Helsinki, p.59-66.

(1995b) L'Imperfeito portugais: étude sistématique de ses fonctions et de comment en rendre compte en traduisant vers l'anglais. Actes du XXIème Congrès de Linguistique et Philologie Romanes (Palermo, 18-24 Séptembre 1995), à paraître.

(1996) Tense and aspect in English and Portuguese: a contrastive semantical study. Tese de doutoramento, Instituto Superior Técnico, Universidade Técnica de Lisboa, Junho de 1996.

(No prelo,a) O tradutês na literatura infantil traduzida em Portugal. In: Actas do XII Encontro da Associação Portuguesa de Linguística (Lisboa, 1-3 de Outubro de 1997). 

. (No prelo, $b$ ) Perception verbs in English and Portuguese. In: JOHANSSON, S. \& OKSEFJELL, S. (eds.) Corpora and Crosslinguistic Research: Theory, Method, and Case Studies. Amsterdam/Atlanta, Rodopi.

SAPIR, E. (1944) On grading: a study in semantics. Philosophy of Science 2, p.93-116.

TAYLOR, J. R. (1989) Linguistic categorization: Prototypes in Linguistic Theory. Oxford, Clarendon Press. 